\title{
Advanced modelling of the transport phenomena across horizontal clothing microclimates with natural convection
}

\author{
T. S. Mayor ${ }^{1} \cdot$ S. Couto $^{2} \cdot$ A. Psikuta $^{1} \cdot$ R. M. Rossi ${ }^{1}$
}

Received: 4 August 2014 /Revised: 6 April 2015 / Accepted: 6 April 2015 /Published online: 21 May 2015

(C) ISB 2015

\begin{abstract}
The ability of clothing to provide protection against external environments is critical for wearer's safety and thermal comfort. It is a function of several factors, such as external environmental conditions, clothing properties and activity level. These factors determine the characteristics of the different microclimates existing inside the clothing which, ultimately, have a key role in the transport processes occurring across clothing. As an effort to understand the effect of transport phenomena in clothing microclimates on the overall heat transport across clothing structures, a numerical approach was used to study the buoyancy-driven heat transfer across horizontal air layers trapped inside air impermeable clothing. The study included both the internal flow occurring inside the microclimate and the external flow occurring outside the clothing layer, in order to analyze the interdependency of these flows in the way heat is transported to/from the body. Two-dimensional simulations were conducted considering different values of microclimate thickness $(8,25$ and $52 \mathrm{~mm})$, external air temperature ( 10 , 20 and $\left.30{ }^{\circ} \mathrm{C}\right)$, external air velocity $\left(0.5,1\right.$ and $\left.3 \mathrm{~m} \mathrm{~s}^{-1}\right)$ and emissivity of the clothing inner surface (0.05 and 0.95$)$, which implied Rayleigh numbers in the microclimate spanning 4 orders of magnitude $\left(9 \times 10^{2}-3 \times 10^{5}\right)$. The convective heat transfer coefficients obtained along the clothing were found to strongly depend on the transport phenomena in the
\end{abstract}

\section{T. S. Mayor}

tiago.sottomayor@empa.ch; tiagosmayor@gmail.com

$1 \quad$ Laboratory for Physiology and Protection, Swiss Federal Laboratories for Materials Science and Technology, Empa, Lerchenfeldstrasse 5, 9014 St. Gallen, Switzerland

2 Product Optimization and Characterization Laboratory, CeNTI, Centre for Nanotechnology and Smart Materials, Rua Fernando Mesquita, 2785, 4760-034 Vila Nova de Famalicão, Portugal microclimate, in particular when natural convection is the most important transport mechanism. In such scenario, convective coefficients were found to vary in wavy-like manner, depending on the position of the flow vortices in the microclimate. These observations clearly differ from data in the literature for the case of air flow over flat-heated surfaces with constant temperature (which shows monotonic variations of the convective heat transfer coefficients, along the length of the surface). The flow patterns and temperature fields in the microclimates were found to strongly depend on the characteristics of the external boundary layer forming along the clothing and on the distribution of temperature in the clothing. The local heat transfer rates obtained in the microclimate are in marked contrast with those found in the literature for enclosures with constant-temperature active walls. These results stress the importance of coupling the calculation of the internal and the external flows and of the heat transfer convective and radiative components, when analyzing the way heat is transported to/from the body.

Keywords Natural convection - Buoyancy-driven flows · Clothing microclimates $\cdot$ Air gaps $\cdot$ Radiant transfer $\cdot$ Internal flow and external flow $\cdot$ Flow simulation $\cdot$ Computational fluid dynamics (CFD)

\section{Introduction}

Clothing plays a central role in the protection of the human body against the surrounding environment. In many professional activities (e.g. military personnel, firefighters, cold/hot chamber operators, chemical-biological-radiological-nuclear (CBRN)-protected personnel), clothing is expected to offer efficient protection against potentially health-threatening factors (e.g. heat/cold, hazardous agents), while ensuring a level 
of thermal comfort that is compatible with the tasks to be performed. This dual goal of protection versus comfort poses a great challenge because of the often contradictory requirements, which implies that, for every type of activity, an optimal balance needs to be found between clothing thermal performance and its protective capacity. This requires a solid understanding of the different parameters influencing performance.

Clothing thermal performance depends on different factors, from environmental conditions to activity level, from clothing design to material properties. These factors influence the way clothing and body interact, thus dictating the characteristics of the different microclimates existing inside clothing. Several works in the literature show that the features of these microclimates play a central role in the transport processes across clothing (Torvi et al. 1999; Song 2007; Ding et al. 2010; Kim et al. 2002; Barker et al. 2004; Min et al. 2007; Psikuta et al. 2012; Morrissey and Rossi 2013; Mayor et al. 2014a). In these regions, heat is transported by radiation and conduction or natural convection, depending on the distance and temperature difference between their boundaries. Estimates of average transport rate across microclimates can be obtained with correlations of the Nusselt number as a function of the Rayleigh number (Hollands et al. 1975; Çengel 2007), and its use has been reported while addressing different aspects of fabrics/ clothing performance (Torvi et al. 1999; Ding et al. 2010; Barker et al. 2004; Sawcyn and Torvi 2009; Li et al. 2012). However, these correlations provide no information on the local transport rates inside the microclimates, which influence local thermal effects, and ultimately, are needed to understand the interactions between fluid flow and heat transfer across clothing.

Different experimental techniques have been used to study clothing microclimates and their effect on heat transfer across clothing. Some researchers report the use of three-dimensional scanning techniques together with data from thermal manikins, in an attempt to relate the features of the clothing microclimates (e.g. thickness, volume) and the heat transfer measured across protective clothing (Song 2007; Kim et al. 2002). Others used different types of heated-guarded hotplates to study the transport rates across microclimates, in a variety of conditions mimicking clothing use (Torvi et al. 1999; Ding et al. 2010; Morozumi et al. 2012). However, despite producing valuable information, these techniques suffer from an intrinsic limitation, which stems from the nature of the assessment that they enable. These techniques allow integral analyses, whose spatial resolution is limited to the dimension of the smaller thermal element existing in the used equipment, be it the plate when using a heated hotplate, or the individual manikin zone when using a thermal manikin. This is particularly restrictive when studying microclimates with natural convection, because such transport mechanism may result in complex flow and temperature patterns, leading to marked oscillation in the local transport rates (e.g. heat fluxes) across the microclimates (Corcione 2003; Vivek et al. 2012; Mayor et al. 2014a). By not capturing these local effects, the mentioned techniques skip important information to allow a better understanding of the local transport processes in clothing microclimates. This is becoming more relevant as the complexity of clothing systems increases (e.g. with integration of active heating/cooling elements, embedment of inflatable elements to alter local thermal properties; Couto et al. 2011; Zhao et al. 2013; Scott 2005; Neiva et al. 2011; Neves et al. 2014, 2015b).

Natural convection has received a considerable amount of attention from the research community, given its high importance in many industrial processes, e.g. solar energy systems, double-glazed windows, cooling of electronic components and machinery. Focussing mostly on flat enclosures with constant-temperature active walls (i.e. walls where cold/hot temperature is maintained constant), several aspects of buoyancy-driven flows have been studied for different geometry aspect ratios (Soong et al. 1996; Corcione 2003; Vivek et al. 2012), system orientation (Baïri et al. 2007; Khezzar et al. 2011; Vivek et al. 2012) and position of the active walls (Corcione 2003; Wang and Hamed 2006). However, despite the importance of the mentioned works to our understanding of transport processes in spaces with natural convection, there are fundamental differences between the conditions addressed in these studies and those prevailing in clothing microclimates. The assumption of constant temperature in the active walls implies that the transport processes occurring around the enclosures can be neglected relative to those occurring inside the enclosures. Although this may be reasonable in industrial processes with highly insulated walls/boundaries, it is far less reasonable for clothing products, given their range of different materials and structures. This implies that one should not neglect the effect of the external flow on the local transport processes occurring in the clothing microclimates and the influence of transport processes in the microclimates, on the way heat is transferred from the latter to the surrounding environment.

In light of the above, the transport processes occurring in clothing microclimates were numerically studied for horizontal air layers trapped inside impermeable clothing. The flows inside and outside the microclimate were addressed in a coupled way in order to study their interdependency while considering all relevant transport phenomena (e.g. natural and forced convection as well as radiant exchange inside and outside the microclimate). The effect of different microclimate thicknesses, external environmental conditions (air temperatures and velocities) and fabric optical properties were studied in a systematic way in order to investigate the transport processes from the microclimates to the surrounding environment. 


\section{Simulation model}

\section{Domain geometries and boundary conditions}

The transport phenomena across clothing were studied numerically through an analysis of the fluid flow and heat transfer occurring in clothing microclimates and surrounding environment. Focus was put on the phenomena occurring across flat geometries consisting of a trapped air layer (i.e. the microclimate), a fabric layer (i.e. the clothing) and an external air layer (i.e. the surrounding environment; see Fig. 1).

The analyses were conducted considering several microclimate geometries and environmental conditions to address scenarios found in different human activities. Increasing values of microclimate thickness, external air temperature and external air velocity were considered in three individual studies (studies I, II and III, Table 1). In all the studies, the microclimate aspect ratio ( $A R=L / H$; Fig. 1$)$ was maintained constant by adapting as needed the microclimate's length. In the external air layer, whose thickness was found adequate to ensure the normal formation of the dynamic and thermal boundary layers, air enters the simulation domain with uniform velocity and temperature profiles and flows parallel to the fabric surface. A 1-mm-thick fabric with a thermal resistance of $0.01 \mathrm{~m}^{2} \mathrm{~K} \mathrm{~W}^{-1}$ was considered.

For each study, two scenarios were considered regarding the optical properties of the fabric inner surface. The emissivity of this surface was considered to be either 0.95 or 0.05 , corresponding to fabrics treated with high- and low-emissivity coatings, respectively. The latter addresses the case of the typical infrared-reflective fabrics. For the external fabric surface, a typical cotton fabric emissivity of 0.77 was considered (Zhang et al. 2009; Ding et al. 2010, 2011). The vertical boundaries of the microclimate were taken as adiabatic and perfect radiators $(\varepsilon=0)$ to minimize their influence in the total heat transport.

The microclimate lower boundary (representing skin or a heated-guarded hotplate) was considered to have a constant

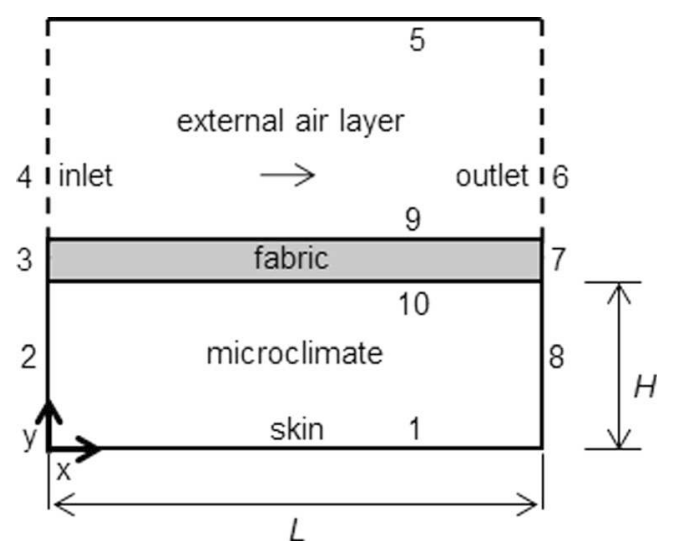

Fig. 1 Representation of the domain used in the analysis (microclimate+ fabric + external air layer) with labels used for each boundary
Table 1 Environmental conditions and domain geometries considered in each parametric study

\begin{tabular}{lllll}
\hline & Units & Study I & Study II & Study III \\
\hline Air temperature & ${ }^{\circ} \mathrm{C}$ & 10 & $10,20,30$ & 10 \\
Air velocity & $\mathrm{m} \mathrm{s}^{-1}$ & 0.5 & 0.5 & $0.5,1,3$ \\
Microclimate thickness & $\mathrm{mm}$ & $8,25,52$ & 37.5 & 37.5 \\
Microclimate length & $\mathrm{mm}$ & $32,100,208$ & 150 & 150 \\
Fabric thickness & $\mathrm{mm}$ & 1 & 1 & 1 \\
External air layer thickness & $\mathrm{mm}$ & 50 & 50 & 50 \\
\hline
\end{tabular}

temperature of $36{ }^{\circ} \mathrm{C}$ and a surface emissivity of 0.95 (Ding et al. 2010). A summary of the conditions used in the study is given in Tables 1 and 2 .

\section{Modelling assumptions and approach}

The internal flow was considered to be two dimensional, steady and laminar (Baïri et al. 2007; Khezzar et al. 2011; Lartigue et al. 2000; Davis 1983; Souza et al. 2003; Vierendeels et al. 2003; Corcione 2003; Lee and Ha 2005). The external flow was also considered to occur in the laminar regime because the Reynolds number along the geometry length is always lower than the critical value of $3.5 \times 10^{5}$, for all conditions considered in this study (Coulson et al. 1999; Lienhard and Lienhard 2003).

The fluid was assumed incompressible with constant properties (obtained at the reference temperature, i.e. the average temperature between the microclimate lower boundary and the environment). The buoyancy effects in the microclimate were implemented considering the Boussinesq approximation. The latter is applicable for scenarios with small temperature differences, such as the case in the study, and implies that the variations in fluid density have a negligible effect on the flow field except for the case of buoyancy forces (Bejan and Kraus 2003). Buoyancy effects were discarded in the external flow due to the much more relevant effect of forced convection.

The fluid flow and heat transfer occurring in the simulation domain were described by the classical set of continuity, momentum (Navier-Stokes) and energy equations (Leal 2007):

$\nabla \cdot \boldsymbol{u}=0$

$\rho_{0}(\boldsymbol{u} \cdot \nabla) \boldsymbol{u}=-\nabla p+\nabla \cdot \mu\left(\nabla \boldsymbol{u}+(\nabla \boldsymbol{u})^{T}\right)+\boldsymbol{F}$

$\rho_{0} C_{p} \boldsymbol{u} \cdot \nabla T-\nabla \cdot(k \nabla T)=0$

where $\nabla$ is the differential (nabla) operator; $\boldsymbol{u}$ is the fluid velocity vector $\left(\mathrm{m} \mathrm{s}^{-1}\right) ; p$ is the pressure $(\mathrm{Pa}) ; T$ is the temperature $(\mathrm{K}) ; k$ is the thermal conductivity $\left(\mathrm{W} \mathrm{m}^{-1} \mathrm{~K}^{-1}\right) ; \rho_{0}$ is the reference density $\left(\mathrm{kg} \mathrm{m}^{-3}\right)$, obtained at the reference temperature $\left(T_{0}\right) ; \mu$ is the fluid dynamic viscosity $\left(\mathrm{Pa} \mathrm{s}^{-1}\right) ; C_{p}$ is the 
Table 2 Boundary conditions (BCs) considered in the simulation domain (BC labels according to Fig. 1)

\begin{tabular}{llll}
\hline Boundary & Description & Fluid flow & Heat transfer \\
\hline 1 & Skin & No slip: $\boldsymbol{u}=0$ & $T=36, \varepsilon=0.95$ \\
2,8 & Microclimate walls & No slip: $\boldsymbol{u}=0$ & Adiabatic: $\boldsymbol{n} \cdot \boldsymbol{q}=0 ; \varepsilon=0$ \\
3,7 & - & Adiabatic: $\boldsymbol{n} \cdot \boldsymbol{q}=0$ \\
4 & Fabric walls & $u_{x}=u_{\text {air }}, u_{y}=0$ & $T=T_{\text {air }}$ \\
5 & Inlet (cf. Table 1) & Symmetry $: \boldsymbol{u n}=0$ & Symmetry $: \boldsymbol{n} \cdot \boldsymbol{q}=0$ \\
6 & Environment & $p=0$ & - \\
9 & Outlet & No slip: $\boldsymbol{u}=0$ & $\varepsilon=0.77$ \\
10 & Fabric outer surface & No slip: $\boldsymbol{u}=0$ & $\varepsilon=0.95$ or $\varepsilon=0.05$ \\
\hline
\end{tabular}

$\boldsymbol{u}$ velocity vector, $\boldsymbol{n}$ vector of directions normal to the boundary, $\boldsymbol{q}$ heat flux vector

${ }^{a}$ Although a null shear stress $\mathrm{BC}$ would be more realistic in boundary 5 , preference was given to a symmetry $\mathrm{BC}$ for the sake of faster/easier convergence, because both alternatives result in similar temperature and velocity distributions along and across the external air layer specific heat capacity of the fluid $\left(\mathrm{J} \mathrm{kg}^{-1} \mathrm{~K}^{-1}\right)$; and $\boldsymbol{F}$ is the buoyancy force acting on the fluid elements $\left(\mathrm{N} \mathrm{m}^{-3}\right)$. The vertical component of the buoyancy force was implemented using the Boussinesq approximation:

$F_{y}=\rho_{0} g \beta\left(T-T_{0}\right)$

where $g$ is the gravity acceleration $\left(\mathrm{m} \mathrm{s}^{-2}\right)$, and $\beta$ is the coefficient of volumetric thermal expansion $\left(\mathrm{K}^{-1}\right)$.

The radiant exchanges in the domain were calculated using the surface-to-ambient model in the layer representing the external flow (to account for the radiant losses from the fabric outer surface to the environment) and the surface-to-surface model in the layer representing the internal flow (to account for the radiant exchanges between the fabric inner surface and the microclimate lower boundary). In the latter, the radiant heat transfer depends on the view factors between the several surfaces exchanging radiation, which are functions of their spatial arrangement (i.e. distance and length).

\section{Grid tests, convergence criteria and computational requirements}

Grid tests were conducted for all the tested conditions to identify the grid characteristics that ensure grid-independent results. Different grids were used in the three layers of the simulation domain by adapting, as needed, the corresponding maximum sizes of the grid elements. Grid-independent results were obtained when a minimum of 80,25 and 80 grid elements were vertically distributed in the microclimate, fabric and external air layers, respectively. This resulted in a minimum of 240 grid elements horizontally distributed across the domains' length. Higher clustering of the grid elements was considered in the vicinity of boundaries to accurately capture the heat and momentum transport in those locations (e.g. in the boundary layer forming over the fabric surface).

Solutions were considered to be fully converged when the normalized residuals were smaller than $10^{-6}$. In addition, the heat and momentum imbalances in the system (i.e. the error in the conservation of heat and momentum in the system) were taken as a further indicator of solutions accuracy; the global heat imbalance was always lower than $1 \%$, and the momentum imbalance (in the external air layer) was even smaller. The simulations were performed following a finite element method (FEM), using a Core I7 2.80-GHz PC, with 64 GB RAM.

\section{Definition of relevant model variables}

The convective heat transfer coefficient $\left(\mathrm{W} \mathrm{m}^{-2} \mathrm{~K}^{-1}\right)$ obtained along the length of the fabric is obtained by

$h_{c}=\frac{q_{\mathrm{conv}}^{\text {outer }}}{T_{\text {fabric }}^{\text {outer }}-T_{\mathrm{amb}}}$

where $T_{\text {fabric }}^{\text {outer }}$ is the temperature of the fabric outer surface $(\mathrm{K}), T_{\mathrm{amb}}$ is the temperature of the air far from the fabric (i.e. the temperature of the free stream, K), and $q_{\text {conv }}^{\text {outer }}$ is the convective heat flux obtained along the fabric outer surface $\left(\mathrm{W} \mathrm{m}^{-2}\right)$.

For easier comparison of our results with those in the available literature, two dimensionless parameters are used to characterize the extent of heat transfer across the microclimate and the corresponding complexity of the flow, i.e. the Nusselt and Rayleigh numbers, respectively.

The Nusselt number $(\mathrm{Nu})$, relating the total heat transfer along the microclimate lower boundary with the theoretical conductive transfer in purely conductive regime, was calculated by considering both the convective and radiative components $\left(\mathrm{Nu}_{\mathrm{C}}\right.$ and $\mathrm{Nu}_{\mathrm{R}}$, respectively) in order to obtain information on the importance of each transport mechanisms in the overall heat transport:

$\mathrm{Nu}=\mathrm{Nu}_{\mathrm{C}}+\mathrm{Nu}_{\mathrm{R}}$

where each component was obtained following the usual definition (Çengel 2007) 


$$
\begin{aligned}
& \mathrm{Nu}_{\mathrm{C}}=\frac{\bar{q}_{\text {conv }}}{\bar{q}_{\text {cond }}}=\frac{\bar{q}_{E}}{k \cdot\left(T_{\text {skin }}-\bar{T}_{\text {fabric }}^{\text {inner }}\right) / H} \\
& \mathrm{Nu}_{\mathrm{R}}=\frac{\bar{q}_{\text {rad }}}{\bar{q}_{\text {cond }}}=\frac{\bar{q}_{\text {rad }}}{k \cdot\left(T_{\text {skin }}-\bar{T}_{\text {fabric }}^{\text {inner }}\right) / H}
\end{aligned}
$$

In these expressions, $\bar{q}_{\text {conv }}$ and $\bar{q}_{\text {rad }}$ are the average convective and radiant heat fluxes observed along the microclimate lower boundary (i.e. the skin), whereas $\bar{q}_{\text {cond }}$ is the average conductive heat flux that would be obtained in purely conductive regime $\left(\mathrm{W} \mathrm{m}^{-2}\right)$. Moreover, $k$ is the thermal conductivity of the fluid ( $\left.\mathrm{W} \mathrm{m}^{-1} \mathrm{~K}^{-1}\right), T_{\text {skin }}$ is the skin temperature $(\mathrm{K})$, $\bar{T}_{\text {fabric }}^{\text {inner }}$ is the average temperature of the fabric inner surface $(\mathrm{K})$, and $H$ is the thickness of the microclimate (m).

In the above expressions, the average value of parameters changing along the length of the domain (e.g. $\bar{T}_{\text {fabric }}, \bar{q}_{\text {conv }}$ and $\bar{q}_{\text {rad }}$ ) was obtained by integration along the domain, as follows:

$\bar{z}=1 / L \int_{0}^{L} z(x) d x$

where $z$ refers to the variable being averaged, and $L$ is the length of the domain (m).

The Rayleigh number ( $\mathrm{Ra})$, defined as the product of the Grashof number (Gr, describing the relation between buoyancy and viscous forces) and the Prandtl number (Pr, describing the relation between momentum and thermal diffusivities), was obtained using (Çengel 2007)

$\mathrm{Ra}=\mathrm{Gr} \cdot \operatorname{Pr}=\frac{g \cdot \beta \cdot\left(T_{\text {skin }}-\bar{T}_{\text {fabric }}^{\text {inner }}\right) \cdot H^{3}}{\nu^{2}} \cdot \operatorname{Pr}$

where $g$ is the acceleration of gravity $\left(\mathrm{m} \mathrm{s}^{-2}\right), \beta$ is the air thermal expansion coefficient $\left(\mathrm{K}^{-1}\right)$, and $v$ is its kinematic viscosity $\left(\mathrm{m}^{2} \mathrm{~s}^{-1}\right)$. The Rayleigh number, which can be seen as an indicator of flow complexity, is usually used to characterize the transition between conduction-dominated and convection-dominated heat transfer. For flat enclosures with horizontal constant-temperature active walls, this transition is reported to occur for a critical Rayleigh number of 1708 (Çengel 2007).

\section{Validation of modelling approach}

For validation purposes, the present modelling and numerical approach was used to replicate several studies from the literature involving buoyancy-driven flows in enclosures (Soong et al. 1996; Wang and Hamed 2006; Vivek et al. 2012; Cuckovic-Dzodzo et al. 1999; Corcione 2003; Davis 1983) as well as external convective flows over flat plates (Çengel
2007; Coulson et al. 1999; Lienhard and Lienhard 2003) and radiant heat exchange between plates (Çengel 2007). Table 3 shows a summary of the average Nusselt numbers obtained for buoyancy-driven flows in enclosures with several aspect ratios (in the range 1-4) and Rayleigh numbers (in the range $10^{3}-10^{6}$ ). The consistency between the present data and the published results is clear, as shown by the small relative differences obtained (below $1.2 \%$, for all the tested cases). The predictions for the radiant heat exchange were compared with literature data for the case of infinite flat parallel plates (Çengel 2007) and for buoyancy-driven flows in cavities (Vivek et al. 2012) (as shown in Table 3), with deviations being smaller than 0.03 and $0.7 \%$, respectively. The results of the present model for the convective flow in the external air layer were also compared with literature data regarding laminar external flows over flat hotplates (Lienhard and Lienhard 2003). Figure 2 shows this comparison focusing on the profiles of temperature and convective coefficient, obtained along the length of the hot surface. The agreement between the predictions of our model and those from previously published works confirms the adequacy of the modelling and numerical approach followed in this study.

\section{Results and discussion}

The influence of different parameters over the heat transfer from the skin to the environment is discussed in this section. Special attention is put on the steady-state transport phenomena in the microclimate, in the external air layer and in the interdependency between the two, followed by a discussion on the implications of the findings, in different application fields. The analysis was initiated using the implemented model to study the transport phenomena in horizontal flat geometries for three different microclimate thicknesses and constant external air velocity and temperature (cf. Table 1, study I).

\section{Transport phenomena in the microclimate (internal flow)}

The temperature and velocity maps obtained in the microclimates are shown in Fig. 3 together with the corresponding temperature isotherms and flow streamlines. For the sake of clarity, the maps in the figure are shown with different magnifications (to ensure the same height and length in the figure).

Despite the constant aspect ratio of the microclimate $(A R=$ 4 ), the three tested thicknesses lead to totally different flow patterns in the microclimate. The thinner microclimate $(8 \mathrm{~mm})$ implies heat transfer in pure conductive regime, as shown by the almost parallel and horizontal isotherms (Fig. 3(a)) and the absence of flow vortices (Fig. 3(b)). The thicker microclimates (25 and $52 \mathrm{~mm}$ ) lead to different degrees of convective heat transfer, as indicated by the different (but typical) mushroom- 
Table 3 Summary of Nusselt numbers obtained from the literature and in the present study for various aspect ratios (ARs) and Rayleigh numbers (Ra)

\begin{tabular}{|c|c|c|c|c|c|c|}
\hline & $\mathrm{AR}$ & $\mathrm{Ra}$ & $\mathrm{Nu}_{\text {present }}$ & $\mathrm{Nu}_{\text {ref. }}$ & \% Dev. & Phenomena \\
\hline \multirow[t]{3}{*}{ Davis (1983) } & \multirow[t]{3}{*}{1} & $1 \times 10^{4}$ & 2.243 & 2.243 & -0.02 & \multirow[t]{3}{*}{ Convection } \\
\hline & & $1 \times 10^{5}$ & 4.516 & 4.519 & 0.06 & \\
\hline & & $1 \times 10^{6}$ & 8.802 & 8.800 & -0.02 & \\
\hline \multirow[t]{3}{*}{ Soong et al. (1996) } & \multirow[t]{3}{*}{4} & $2 \times 10^{3}$ & 1.116 & 1.120 & 0.36 & \multirow[t]{3}{*}{ Convection } \\
\hline & & $5 \times 10^{3}$ & 2.008 & 1.989 & -0.96 & \\
\hline & & $2 \times 10^{4}$ & 3.088 & 3.054 & -1.11 & \\
\hline \multirow{3}{*}{$\begin{array}{l}\text { Wang and Hamed } \\
\text { (2006) }\end{array}$} & \multirow[t]{3}{*}{4} & $1 \times 10^{3}$ & 1.000 & 1.000 & 0.00 & \multirow[t]{3}{*}{ Convection } \\
\hline & & $3 \times 10^{3}$ & 1.559 & 1.561 & -0.13 & \\
\hline & & $5 \times 10^{3}$ & 2.008 & 2.017 & -0.45 & \\
\hline \multirow[t]{4}{*}{ Vivek et al. (2012) } & \multirow[t]{4}{*}{1} & $1 \times 10^{5}$ & $4.096\left(\mathrm{Nu}_{\mathrm{C}}\right)$ & $4.099\left(\mathrm{Nu}_{\mathrm{C}}\right)$ & -0.07 & \multirow{4}{*}{$\begin{array}{l}\text { Convection } \\
\quad+\text { radiation }\end{array}$} \\
\hline & & & $6.892\left(\mathrm{Nu}_{\mathrm{R}}\right)$ & $6.937\left(\mathrm{Nu}_{\mathrm{R}}\right)$ & -0.65 & \\
\hline & & \multirow[t]{2}{*}{$1 \times 10^{6}$} & $7.642\left(\mathrm{Nu}_{\mathrm{C}}\right)$ & $7.680\left(\mathrm{Nu}_{\mathrm{C}}\right)$ & -0.49 & \\
\hline & & & $14.939\left(\mathrm{Nu}_{\mathrm{R}}\right)$ & $15.040\left(\mathrm{Nu}_{\mathrm{R}}\right)$ & -0.67 & \\
\hline
\end{tabular}

$\mathrm{Nu}_{\text {present }}$ and $\mathrm{Nu}_{\text {ref. }}$ refer to the Nusselt numbers obtained in our simulations and in the reference studies, respectively; \% Dev. is the relative difference between the two Nusselt numbers shaped isotherms (Fig. 3(c, e)) and the several vortices seen in the velocity maps (Fig. 3(d, f)).

The fact that the thinner microclimate did not yield natural convection was expected because the corresponding average Rayleigh number (907) is far below the critical value of 1708 , which is known to mark the onset on natural convection in horizontal flat enclosures with constant-temperature active walls (Çengel 2007). Furthermore, the increasing complexity of the flow pattern with increasing microclimate thickness is also consistent with the variation in the corresponding Rayleigh numbers, which span 4 orders of magnitude for the tested microclimate thicknesses (Table 4). Given the dependency of this dimensionless number on the ratio between the buoyancy and viscous forces (i.e. the Gr), the increasing Rayleigh number is a direct indicator of increasing importance of buoyancy forces and, hence, of natural convection intensity, as the microclimate thickness increases.

The increasing intensity of natural convection as microclimate thickness increases is evident in the velocity of the fluid elements in the microclimate (Fig. 3(b, d, f)) and in the corresponding average Nusselt numbers, which show an approximate sixfold increase as thickness augments from 8 to $52 \mathrm{~mm}$

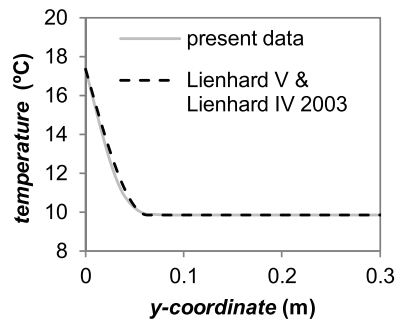

a

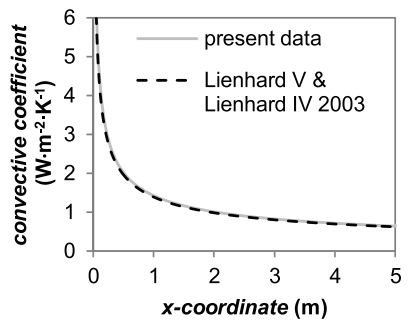

b
Fig. 2 Comparison of the present numerical results with predictions from expressions in the literature (Lienhard and Lienhard 2003) for a temperature profile along the external air layer and $\mathbf{b}$ heat transfer coefficient along the fabric outer surface (see $\overline{\mathrm{Nu}}_{\mathrm{C}}$ in Table 4). Interestingly, despite this marked increase in convection intensity with increasing thickness, the average convective heat fluxes observed at the skin decrease by $17-31 \%$ (depending on the optical properties of the fabric inner surface; Fig. 4). This variation, however, is very small
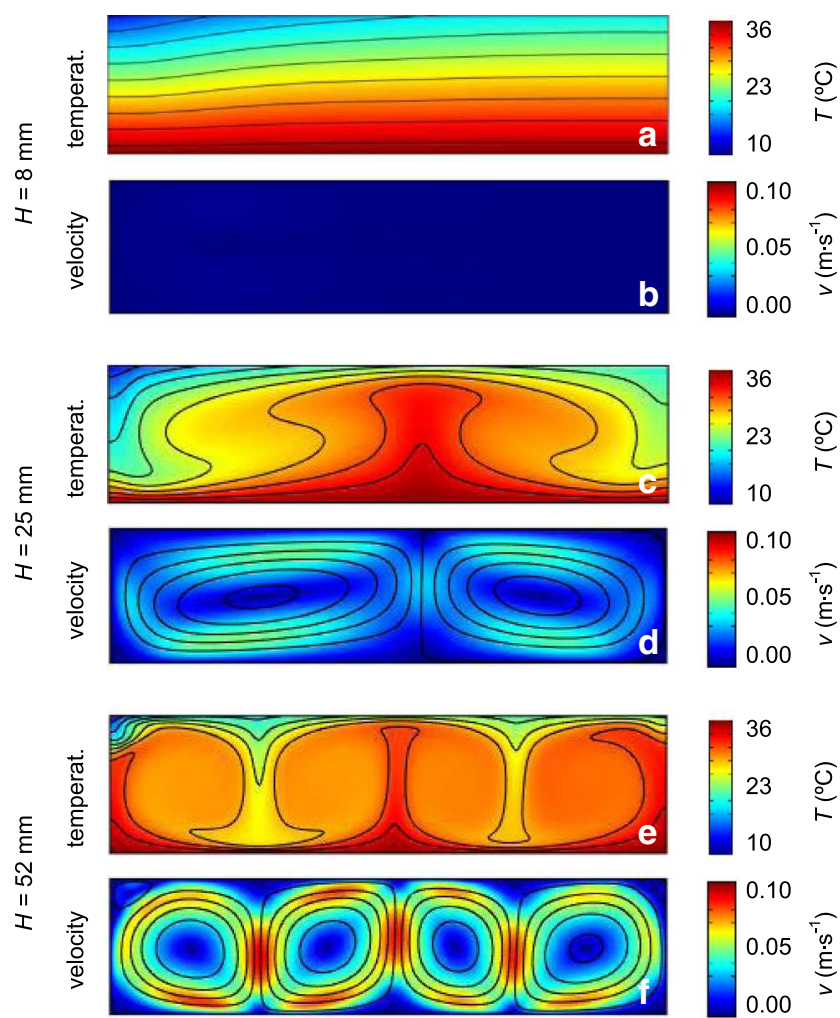

Fig. $3 a-f$ Temperature and velocity maps (and corresponding isotherms and streamlines) in the microclimate for microclimate thicknesses of 8, 25 and $52 \mathrm{~mm}$ and fabric inner surface with high emissivity; simulation conditions are as given in Table 1 (study I); the maps for each microclimate thickness are shown with different magnifications though with constant aspect ratio $(A R=L / H)$ 
Table 4 Average (convective and radiant) Nusselt numbers and Rayleigh numbers obtained in the microclimate for the different conditions considered in each study

\begin{tabular}{|c|c|c|c|c|c|c|c|c|c|}
\hline & \multirow[t]{2}{*}{ Parameter } & \multicolumn{4}{|c|}{ Fabric inner emissivity: $\varepsilon=0.95$} & \multicolumn{4}{|c|}{ Fabric inner emissivity: $\varepsilon=0.05$} \\
\hline & & $\overline{\mathrm{Nu}}_{\mathrm{C}}$ & $\overline{\mathrm{Nu}}_{\mathrm{R}}$ & $\overline{\mathrm{Nu}}$ & $\overline{\mathrm{Ra}}$ & $\overline{\mathrm{Nu}}_{\mathrm{C}}$ & $\overline{\mathrm{Nu}}_{\mathrm{R}}$ & $\overline{\mathrm{Nu}}$ & $\overline{\mathrm{Ra}}$ \\
\hline \multirow[t]{3}{*}{ Study I } & $H=8 \mathrm{~mm}$ & 1.00 & 1.53 & 2.54 & $9.07 \times 10^{2}$ & 1.00 & 0.09 & 1.09 & $1.11 \times 10^{3}$ \\
\hline & $H=25 \mathrm{~mm}$ & 2.86 & 4.82 & 7.67 & $2.43 \times 10^{4}$ & 3.02 & 0.29 & 3.31 & $3.13 \times 10^{4}$ \\
\hline & $H=52 \mathrm{~mm}$ & 5.50 & 10.10 & 15.59 & $2.02 \times 10^{5}$ & 6.04 & 0.60 & 6.64 & $2.71 \times 10^{5}$ \\
\hline \multirow[t]{3}{*}{ Study II } & $T_{\text {air }}=10^{\circ} \mathrm{C}$ & 4.23 & 7.26 & 11.49 & $7.83 \times 10^{4}$ & 4.54 & 0.43 & 4.98 & $1.03 \times 10^{5}$ \\
\hline & $T_{\text {air }}=20^{\circ} \mathrm{C}$ & 3.70 & 7.35 & 11.05 & $4.55 \times 10^{4}$ & 3.99 & 0.44 & 4.43 & $6.05 \times 10^{4}$ \\
\hline & $T_{\text {air }}=30^{\circ} \mathrm{C}$ & 2.84 & 7.46 & 10.30 & $1.63 \times 10^{4}$ & 3.08 & 0.45 & 3.53 & $2.21 \times 10^{4}$ \\
\hline \multirow[t]{3}{*}{ Study III } & $v_{\text {air }}=0.5 \mathrm{~m} \mathrm{~s}^{-1}$ & 4.23 & 7.26 & 11.49 & $7.83 \times 10^{4}$ & 4.54 & 0.43 & 4.98 & $1.03 \times 10^{5}$ \\
\hline & $v_{\mathrm{air}}=1.0 \mathrm{~m} \mathrm{~s}^{-1}$ & 4.30 & 7.22 & 11.53 & $8.48 \times 10^{4}$ & 4.58 & 0.43 & 5.01 & $1.08 \times 10^{5}$ \\
\hline & $v_{\mathrm{air}}=3.0 \mathrm{~m} \mathrm{~s}^{-1}$ & 4.42 & 7.17 & 11.58 & $9.51 \times 10^{4}$ & 4.64 & 0.43 & 5.07 & $1.15 \times 10^{5}$ \\
\hline
\end{tabular}

when compared to the 6.5 -fold increase in the thickness of the tested microclimates. Ultimately, this confirms the importance of convective transport in the two thicker microclimates. Further details on the effect of changing microclimate thickness over the convective and radiant transport are discussed in the "Role of the fabric optical properties" section.

The increasing complexity of the flow pattern inside the microclimate due to the increase of its thickness has several implications. Firstly, there is an increase in the number of counter-rotating vortices in the microclimate (from 0 to 2 or 4 , as the thickness increases from 8 to 25 or $52 \mathrm{~mm}$, respectively) as well as the already mentioned marked augmentation in the velocity of the fluid elements (Fig. 3(b, d, f)). This produces totally different temperature distributions in the microclimate (Fig. 3(a, c, e)), with clearly different temperature gradients near the skin and near the fabric. For this reason, the local heat fluxes observed along these two boundaries are different, as they are dependent on the surrounding temperature gradients. This is visible in Fig. 5a, where the obtained temperature field is shown together with the heat fluxes along the skin and along the fabric, to highlight the consistency between both parameters. The skin and fabric heat fluxes oscillate in an opposite way, depending on the local temperature

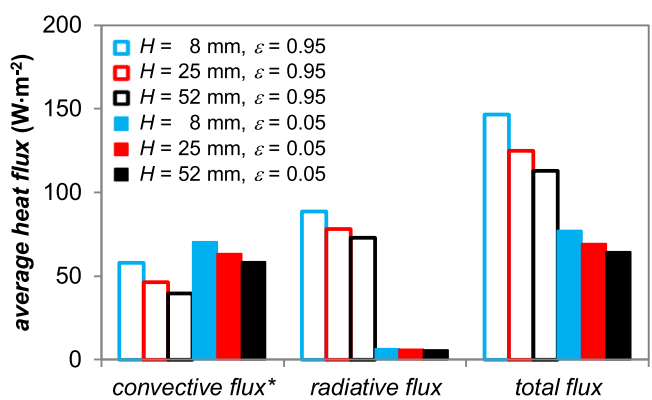

Fig. 4 Average heat fluxes observed at the skin for microclimate thicknesses of 8,25 and $52 \mathrm{~mm}$ and fabric inner surface with high or low emissivity; asterisk since there is no convective transport for $H=$ $8 \mathrm{~mm}$, the corresponding bars represent the heat transferred by conduction gradients prevailing in the microclimate. For the conditions addressed in this figure, the heat fluxes vary up to $100 \%$ along the skin and $50 \%$ along the fabric, with consecutive peaks as close as $9 \mathrm{~cm}$ ( or $x / H \approx 1.7$ in dimensionless form). Nevertheless, these heat flux curves vary with the chosen microclimate thickness because that affects the flow pattern and temperature fields prevailing in the microclimate. This is evident in Fig. 5b, where the mentioned fluxes are plotted along the microclimate length, for the three thicknesses under consideration. In this figure, one clearly observes that it is the occurrence and extent of natural convection that determines the difference between the heat fluxes observed along the skin and fabric. As such, for the lower thickness, which produces no natural convection in the microclimate, the skin and fabric heat fluxes are fairly similar (except for the very left portion of the microclimate where the external boundary layer is very thin and thus the heat flux at the fabric is very high). For the thicker microclimates, the curves have very distinct shapes, depending on the number and position of vortices forming inside the microclimate.

The evident differences between the heat fluxes curves along the skin and fabric are a clear indicator of the potential errors that would occur if trying to predict heat transfer at the
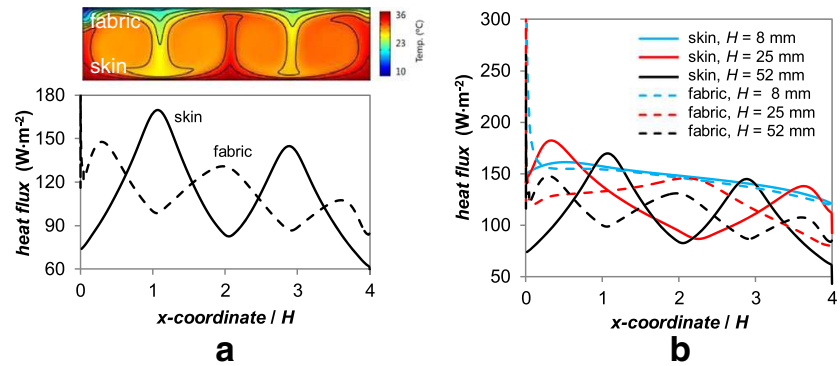

Fig. 5 a Temperature map and corresponding isotherms (upper chart), together with the heat fluxes observed along the skin and along the fabric (lower chart), for a microclimate thickness of $52 \mathrm{~mm}$. b Heat fluxes observed along the skin and along the fabric for microclimate thicknesses of 8,25 and $52 \mathrm{~mm}$; results for fabric inner surface with high emissivity $(\varepsilon=0.95)$ 
skin level through observations at the fabric level, when natural convection is expected to occur in the microclimates. That can be the case in experimental works on the heat transfer in thick highly porous assemblies (or assemblies with embedded air gaps), with heat fluxes sensors spread within the assemblies. If natural convection occurs inside such assemblies, it is critically important that the sensors be positioned in a dense grid, to capture the entire variation of the heat fluxes along the samples; this is relevant because very small changes in the positioning of sensors may result in substantial changes in their readings.

On the other hand, the obtained results are also indicative of the shortcomings of correlations of the Nusselt number as a function of the Rayleigh number (e.g. $\mathrm{Nu}=C \cdot \mathrm{Ra}_{L}^{n}$ (Çengel 2007) or a more complex version such as $\mathrm{Nu}=1+1.44 \cdot[1-$ $1708 / \mathrm{Ra}]+\left[(\mathrm{Ra} / 5830)^{1 / 3}-1\right]($ Hollands et al. 1975)), which are often used to estimate the average heat transport across clothing microclimates (Torvi et al. 1999; Ding et al. 2010; Barker et al. 2004; Sawcyn and Torvi 2009; Li et al. 2012). Given the marked variation of heat transfer rates across and along the microclimate (Fig. 5), the estimates of average heat transfer obtained with the mentioned correlations can differ substantially from the rates observed locally, which may render them unfit when high spatial resolution is advisable and/or necessary (e.g. development of products with localized heating/cooling elements or, in general, to investigate local heat transfer in spaces affected by natural convection). For these activities, preference should be given to approaches such as in this study, where the fluid flow inside the microclimate, is duly taken into consideration.

\section{Role of the external boundary layer}

Unlike enclosure-based studies whose active boundaries (e.g. cold or hot surfaces) are considered to have constant temperature (Soong et al. 1996; Wang and Hamed 2006; Vivek et al. 2012; Corcione 2003), in the present study, we considered both the internal and external flows together. This allowed the fabric temperature to evolve naturally as the result of the heat transfer across its structure and allowed capturing the influence of the boundary layer forming along the external fabric surface. The thickening of the boundary layer along the fabric implies, as expected, a reduction in the transport rate from the internal to the external flow, which is evident in the gradual decrease of the heat flux peaks observed along the skin and fabric (Fig. 5a, lower chart). This is consistent with a general increase of fabric temperature along the microclimate length (Fig. 6), as heat is transferred from the skin to the colder external layer flowing along the fabric.

The general increase of fabric temperature along the microclimate length implies a decrease in the buoyancy forces acting on the fluid elements, because of the reducing temperature difference between the skin and the fabric. As a result, there is

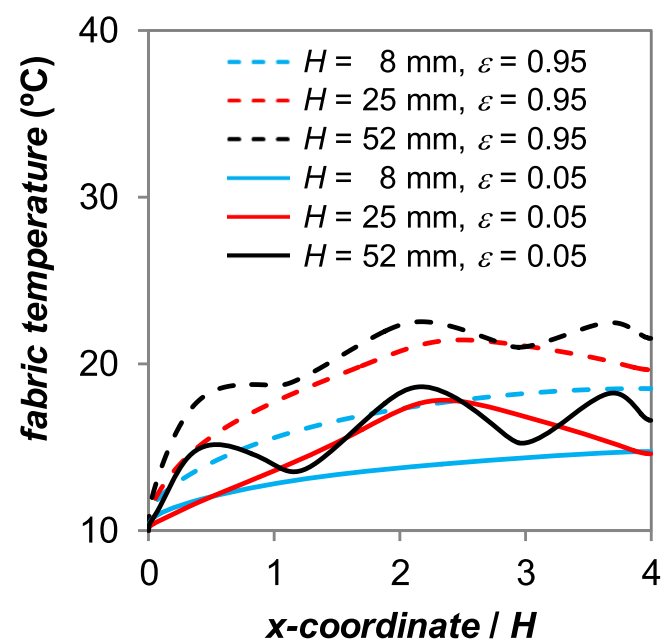

Fig. 6 Temperature of the fabric outer surface for microclimate thicknesses of 8,25 and $52 \mathrm{~mm}$ and fabric inner surface with high or low emissivity

a gradual decrease in the width of the vortices forming in the microclimate (e.g. Fig. 3(f)) and in the width of the mushroom-shaped patterns observed in the temperature contour maps (e.g. Fig. 3(e)). Ultimately, this affects the heat flux curves observed along the skin and fabric, resulting in a decreasing distance between consecutive peaks (Fig. 5b). All these are in marked contrast to the observations in enclosure-based works with constant-temperature active walls (Soong et al. 1996; Wang and Hamed 2006; Vivek et al. 2012; Corcione 2003), where flow vortices, not in contact with the lateral walls, are seen to maintain their width throughout the enclosure, and hence, the resultant transport rates oscillate between constant maxima and minima. Given the evident differences in the result of these two alternative approaches, it follows that it is necessary to address the internal and external flows in a coupled way in order to accurately capture the effects of the external boundary layer on the transport phenomena across clothing microclimates.

\section{Role of the fabric optical properties}

The role of the fabric optical properties, in the heat transfer across the microclimate, was analyzed by considering two different emissivities for the fabric inner surface $(\varepsilon=0.05$ or $\varepsilon=0.95$ ). This allowed taking advantage of the dependence of the radiant transport on the emissivity of the surfaces exchanging heat. The temperature and velocity maps obtained for the thicker microclimate $(52 \mathrm{~mm})$ are shown in Fig. 7.

Changing the emissivity of the fabric inner surface, which influences its capacity to reflect infrared radiation, alters considerably the temperature distribution inside the microclimate, as it is evident in the temperature maps of Fig. 7. The use of a low-emissivity coating in the fabric inner surface results in clearly steeper temperature gradients across the microclimate 


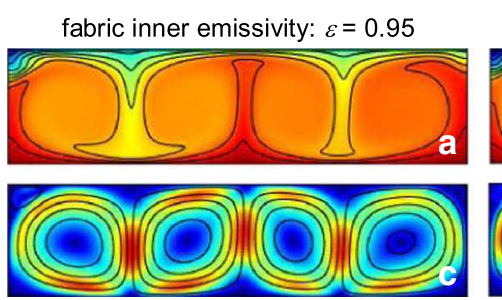

Fig. $7 a-d$ Temperature and velocity maps (and corresponding isotherms and streamlines) in the microclimate for a microclimate thickness of $52 \mathrm{~mm}$ and fabric inner surface with high emissivity $(\varepsilon=0.95$; left fabric inner emissivity: $\varepsilon=0.05$

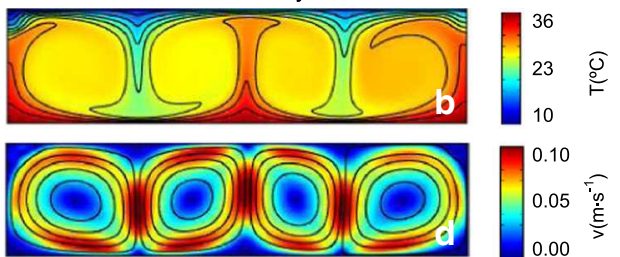

column $)$ and low emissivity ( $\varepsilon=0.05$, right column $)$; simulation conditions are as given in Table 1 (study I)

Furthermore, it is noteworthy that, for the scenario with a high-emissivity fabric (which encompasses many fabrics used in apparel industry), radiation accounts for almost two thirds of the heat transferred from the skin. This confirms the important role of fabric optical properties in the overall heat transfer across microclimates, particularly where air gaps are allowed to exist, and highlights the relevancy of including radiant contribution in analyses of transport phenomena across clothing.

\section{Transport phenomena in the external layer (external flow)}

In order to investigate how heat is transported from the microclimate to the environment, focus is put in the interface between the internal and the external flows, i.e. the fabric surface. Figure $8 \mathrm{a}$ shows the external convective heat transfer coefficient observed along the fabric, for the three microclimate thicknesses under consideration and the two optical scenarios regarding the emissivity of the fabric inner surface.

Attention is called to the fact that the vertical spreading of the several curves of convective heat transfer coefficient (Fig. 8a) is simply the result of the adimensionalization procedure applied to the $x$-coordinate (i.e. division by the corresponding microclimate thickness, $H$ ), which allowed for

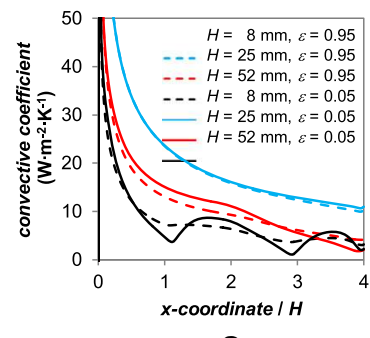

a

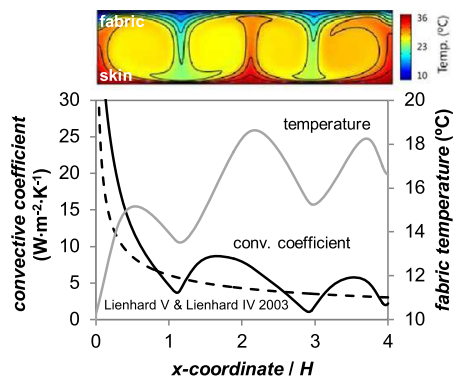

b tune performance according to needs. For instance, besides the direct effect over the total heat transfer (through changes in the radiant component), this offers an indirect way to affect mass transport (e.g. of sweat), through the indirect effect of the optical properties over the level of convection in the microclimate. This effect can be of use, for instance, when changes in a product's geometry or in the materials' transport properties are not possible (e.g. due to design- or requirement-related restrictions).
Fig. 8 a Convective heat transfer coefficients observed along the fabric for increasing microclimate thickness (study I, Table 1) and fabric inner surface with high or low emissivity. b Temperature map and isotherms (upper chart), together with convective heat transfer coefficient and fabric temperature observed along the fabric (lower chart), for a 52-mm-thick microclimate with a low-emissivity fabric inner surface; the correlationbased convective coefficient curve shown in chart (b, dash line) was obtained as $h_{x}=0.332 \cdot k / x \cdot \operatorname{Re}_{x}^{0.5} \cdot \operatorname{Pr}^{1 / 3}$, based on the average fabric temperature obtained in this study 
simpler representation and comparison of the curves, in the same chart.

Some of the curves shown in Fig. 8a do not have the typical shape of the heat transfer coefficient curves, which, for a cold air current flowing over a hot surface, usually display a monotonic decrease along $x$, as the thickness of the boundary layer increases asymptotically along the surface. This is clearly the case for the curves corresponding to the thicker microclimates ( 25 and $52 \mathrm{~mm}$ ), which show increasing complexity in their variation along $x$, in particular those regarding the lowemissivity fabrics. On the contrary, the curves corresponding to the thinner microclimate show the typical monotonic variation along $x$, regardless of the chosen optical scenario. To explain these results, one has to consider the relevance of natural convection occurring in the three microclimates. In the thinner microclimate, no heat is transferred by convection, as indicated by the corresponding Nusselt number (equal to 1 for both optical scenarios; Table 4) and the velocity map of Fig. 3(b). On the contrary, in the thicker microclimates, 91$92 \%$ of the heat is transferred by convection for the case with low-emissivity fabrics (Fig. 4). These results suggest that the heat transfer rate along the fabric outer surface, i.e. the convective coefficient curve obtained along the fabric, is dependent on the natural convection occurring in the microclimate, particularly when such transport mechanism accounts for most of the heat transfer (as is the case for fabrics with a low-emissivity inner surface).

This hypothesis is supported by several aspects of our data. Firstly, an increasing complexity or waviness of the convective coefficient curves is obtained with increasing microclimate thickness (Fig. 8a); as shown by the increase of the corresponding Nusselt number from 1 to 5.5-6 (Table 4), this implies an increasing importance of convection in the microclimate. Secondly, for any of the two microclimate thicknesses that resulted in natural convection, the decrease in the fabric emissivity caused an increase of the complexity or waviness of the convective coefficient curves; again, an increasing importance of convection can be mentioned here, as the proportion of the total Nusselt number that is associated with convection (i.e. $\overline{\mathrm{Nu}}_{\mathrm{C}} / \overline{\mathrm{Nu}}$, Table 4) increases from $37-38$ to $91-$ $91 \%$, when fabric emissivity decreases from 0.95 to 0.05 . Thirdly, the plotting of fabric temperature along the fabric length (Fig. 6) shows clearly more complex and more wavy curves for increasing microclimate thickness and decreasing fabric emissivity. Finally, the consistency between external transport rates and flow patterns in the microclimate is evident in Fig. $8 \mathrm{~b}$, where the fabric temperature and the convective coefficient curves, observed along the fabric for the thicker microclimate, are plotted together with the temperature map observed in the microclimate. In this figure, the local minima of the temperature and convective coefficient curves occur at the horizontal positions where temperature gradients, in the microclimate, are the lowest near the fabric; in other words, the local minima occur where the heat flux along the fabric has its lowest values. As a whole, these effects and consistencies lend support to the idea that the natural convection in the microclimate has a determinant role in the local transport rates along the fabric.

In order to further test the mentioned hypothesis, two further studies were conducted for constant microclimate thickness and increasing temperature or velocity of the external air layer (study II and study III, respectively; Table 1). The convective heat transfer coefficients obtained along the fabric for these two studies are shown in Fig. 9 for the two optical scenarios regarding the fabric inner surface.

As expected, the convective transfer coefficients are seen not to depend on the chosen external temperature (Fig. 9a). However, they show a pronounced dependence on the optical properties of the fabric inner surface. The convective coefficient curves obtained for the low-emissivity fabrics are higher than those obtained for the high-emissivity fabrics for most of the left portion of the microclimate and show a relatively sudden change in the slope around $x / H \approx 1.5$, followed by local minimum and maximum at $x / H \approx 2.7$ and $x / H \approx 3.4$, respectively. A similar trend is observed in the convective transfer coefficients for the study with different external air layer velocities (Fig. 9b). Besides the expected vertical spreading of the curves due to the different thickness of the external boundary layers forming with each chosen air velocity, we observe again a higher complexity in the curves corresponding to the low-emissivity scenario and the mentioned change in pattern (i.e. occurrence of a sudden change in slope, of a local minimum and of a local maximum) at approximately the same horizontal positions. Consistently, these three different horizontal positions coincide, for both studies, with the positions where the heat flux at the fabric (or the temperature gradient in microclimate in the vicinity of the fabric) is either maximum $(x / H \approx 1.5$ and $x / H \approx 3.4)$ or minimum $(x / H \approx 2.7$; not shown graphically for the sake of conciseness). This provides further confirmation that the external transport rate along the fabric is dependent on the natural convection occurring in the microclimate, in particular when convective transport accounts for a
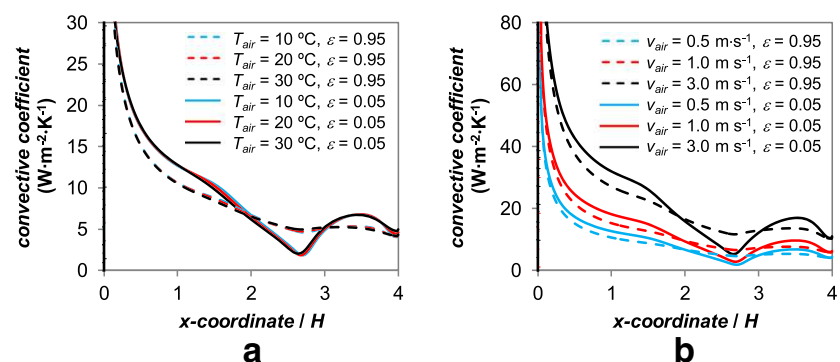

Fig. 9 Convective heat transfer coefficients observed along the fabric, for increasing air layer temperature or velocity, and fabric inner surface with high or low emissivity. a Effect of temperature of external air layer (study II, Table 1). b Effect of velocity of external air layer (study III, Table 1) 
high proportion of the overall heat transfer (as is the case for the low-emissivity fabrics, with infrared-reflective capacity).

To illustrate the relevance of these results, we compared the convective coefficient curve obtained for the thicker microclimate with the low-emissivity fabric, with the correlationbased curve (Lienhard and Lienhard 2003) corresponding to flow over a hot surface with constant temperature $\left(h_{x}=0.332\right.$. $k / x \cdot \operatorname{Re}_{x}^{0.5} \cdot \operatorname{Pr}^{1 / 3}$; Fig. 8 b). For comparison purposes, we based the estimate of fabric temperature of the correlation-based approach on the average value of the fabric temperature obtained in this study. It is evident in Fig. $8 \mathrm{~b}$ that the correlationbased curve is different from the convective coefficient curve obtained in the present work (which accounts for the flow patterns in the microclimate below the fabric). For the specific conditions under comparison, the use of the correlation-based curve would imply errors between $-45 \%$ (at $x / H \approx 1.7$ ) and + $175 \%$ (at $x / H \approx 3$ ), because the correlation does not account for the local effects that are described in this work. From the above differences, it is clear that decisions based on such estimates of local heat transfer may suffer from considerable errors.

\section{Coupling in the flow and heat transfer calculation}

In the previous sections, different aspects of the transport phenomena influencing the heat exchange between the body and the surrounding environment were discussed. The obtained data indicates that an accurate prediction of the local transport rates across and along clothing microclimates can only be obtained if both the internal and the external flows are addressed in a coupled way (Figs. 5, 8 and 9). The results show also a clear interdependency between radiant and convective transport. The extent of these mechanisms determines the local fabric temperature along the microclimates (Fig. 6) and, in turn, the fabric temperatures along the microclimate, and determines the local extent of convection and radiant exchange tacking place along the microclimate and along the fabric (Figs. 4, 8 and 9). This indicates that the calculation of the radiant and convective components should also not be decoupled.

The importance of these coupling strategies augments with decreasing insulation of the clothing and with increasing relative importance of the natural convection in the microclimates (e.g. with infrared-reflective coatings), as such scenarios increase the likelihood of having heterogeneous distribution of temperature along the clothing. A brief summary of the rationale for coupling internal/external flow calculation and for coupling radiation/convection heat transfer calculation is given below, together with a brief contextualization regarding alternative approaches from the literature:

- Coupling is needed to ensure that the flow patterns and temperature distributions obtained inside clothing microclimates are realistic and that they incorporate the phenomena that may affect local heat transfer along the skin (e.g. presence, dimension and position of flow vortices associated with natural convection). These local effects are usually not predicted by correlations relating the Nusselt number with the Rayleigh number of the flow, since they produce only information about the average transport rates (Hollands et al. 1975, 1976; Çengel 2007).

- Coupling is needed to capture existing variations in the local transport rates across clothing, e.g. in the convective coefficients observed along the clothing surface. These can depend on the features of the transport phenomena inside the microclimates, particularly when natural convection plays a dominant role in the overall heat transfer. These dependencies are usually not considered in correlations of the Nusselt number (or of convective coefficient) as a function of the Reynolds number and position along the surface (Çengel 2007).

- Coupling is needed to allow the fabric temperature to evolve as the result of the local heat transfer between the internal and external flows, through the interdependency of radiant and convective transport and the effect of the external boundary layer on the internal transport. The latter is particularly important since the features of the boundary layer depend on several parameters (e.g. clothing geometry, fabric shape or environmental conditions), whose effects are not included in the enclosure-based studies with constant-temperature active walls (Soong et al. 1996; Wang and Hamed 2006; Corcione 2003; Vivek et al. 2012).

\section{Practical implications}

The results discussed in the previous sections may have practical implications in different fields. A brief of description of some practical implications is given below:

- Development of CBRN-protective garments. Accurate knowledge on the transport phenomena in clothing microclimates is of high importance in the development of CBRN garments because of the problems associated with local build-up of agent concentration. The need to understand the effect of flow patterns inside microclimates over the local heat transfer along the skin has a direct parallel in terms of mass transport, e.g. of agent in a CBRN garment. The approaches used in this study can be applied to predict concentration maps of chemical species inside CBRN garments to identify potentially risky spots.

- Development of garments with heating/cooling elements. The introduction of heating/cooling elements in garments may considerably alter the local temperature distributions in the microclimates near the skin. In case the geometrical 
characteristics of such garments give rise to natural convection in their microclimates, it is important to understand how the heating/cooling elements affect the local heat transfer rates in the microclimates, in order to identify potentially problematic transfer rates or hot/cold spots due to unforeseen local interaction of the active elements and the flow patterns developing near the skin.

- Analysis of thermal strain imposed by garments. The prediction of the thermal strain imposed by protective garments relies on the knowledge about the way heat is transported from the skin to the environment. This is usually done through the use of correlations to estimate heat transfer convective coefficients. However, given the discussed shortcomings of some correlations to predict local heat transfer rates along clothing surface, it is advisable to check the accuracy of the correlation-based predictions, for the specific conditions under analysis. When natural convection is expected, an approach like that of the present study can be used to obtain more realistic local heat transfer rates.

- Thermal characterization of fabric assemblies. When studying experimentally the heat (or mass) transfer through thick porous assemblies (e.g. using a sweatingguarded hotplate), it is important to bear in mind that the occurrence of natural convection across their structures may significantly affect the phenomena being monitored. Because of the discussed effect of natural convection on the temperature and heat flux distributions along different regions/surfaces of the assemblies, any sensors used to monitor such parameters should be distributed in a tightly dense grid (i.e. considering small distances between sensors) so that their readings inform about the entire variation, throughout the assemblies, of the parameters being monitored. Failing to do so may lead to misleading readings (i.e. readings that may not capture the entire variation of the mentioned parameters inside the assemblies), which may preclude the full understanding of the transport mechanisms.

\section{Limitations and suggestions of further work}

In this section, limitations and suggestions of further work are briefly presented.

- Microclimate orientation. The approach and results discussed in this work refer to horizontal scenarios, representing, for instance, the geometries occurring when humans are seated (thighs region), reclined or sleeping (e.g. bed, tent or sleeping bag). However, there are other situations that are better described by vertical (e.g. a person standing or working in upright position) or tilted geometries (e.g. arms, legs or body in neither horizontal nor vertical position). In these different orientations (relative to gravity), the flow patterns and the local heat transport rates occurring inside clothing may be very different (Sobera 2006; Mayor et al. 2015). Thus, further studies are needed to promote the full understanding of the way heat that is locally transported from the body to the environment (or vice versa), for any given orientation. This is important when developing, for instance, high performance protective products used around the body (e.g. garments).

- Microclimate geometry. The range of microclimate thicknesses considered in this study $(8-52 \mathrm{~mm})$ is relatively large in order to cover situations where natural convection is unlikely (e.g. thicknesses in the range lower end) and others where it becomes probable (e.g. thicknesses in the range upper end). However, since the distribution of microclimate thicknesses along the body may be very wide (from negligible values near contact zones to substantial air gaps as in CBRN-protective garments) and the geometrical properties of the microclimates (e.g. thickness, length, shape and volume) can have a strong effect on the transport processes to/from the body, further studies are needed to shed light on the controlling parameters and dependence relations, particularly for geometries with larger dimensions, closer to that of the human body. Yet, given the still high computational cost of analyses based on computational fluid dynamics (CFD) as those reported here and the complexity of the above relations, it is important to address the systematic study of these relations in an incremental way, considering geometries as small as possible (but still big enough to represent processes in a realistic way) and increasing its size as the available computational power increases over time. This is important to ensure the optimal pace in terms of calculation, manageable computer memory requirements and reasonable postprocessing times. Examples of such size-wise segmented approach can be found in the literature (Gibson 2009; Rocha et al. 2012; Mayor et al. 2014b).

- Pumping effect. The conditions considered in this study regard static scenarios in which it is reasonable to assume relatively constant microclimate geometries. This is the case for situations implying negligible body motion (e.g. seated, reclining and sleeping). However, in activities implying motion (e.g. walking, running and jumping), the pumping effect caused by the moving body parts (Wang et al. 2011, 2012) and by the changing distance between these relative to the clothing originates complex transport processes within and around clothing, which advise further investigation. As the computational power increases over time, it would be interesting to use numerical (CFD-based) approaches like that of the present work to study the influence of the body movement and the pumping effect on the heat and mass that are transported to/from the body. 
- Mass transport. The present study focuses on the effects of natural convection on the heat transport from the body. Although some of these effects may also be relevant in problems involving mass/sweat transport (since the discussed convective currents inside the clothing microclimate affect the transport of water vapour/sweat in a similar), other relevant effects are not addressed in this work, since they are beyond its scope. This is the case, for instance, of the effect of sweat evaporation/ condensation in the clothing layers (Barker et al. 2004; Neves et al. 2012, 2015a) and its impact on the heat/mass transport from the body. Thus, further studies are needed to investigate the coupled heat and mass transport from the body to the environment, considering both sensible and latent effects (i.e. involving phase change). This is important in an overall strategy of moving towards more integrated numerical approaches, linking various aspects of the problem of heat and mass transport around humans - from the thermoregulation mechanisms of the body to the their impact on the transport processes across the gear used to protect it, e.g. clothing, helmets (Bröde et al. 2014; Bogerd et al. 2015).

\section{Conclusion}

A numerical study was conducted on the transport phenomena across horizontal air layers trapped inside impermeable clothing, using a finite element method. Considering both the internal flow in the microclimate and the external flow around it, in a fully coupled way, the transport phenomena across the microclimates were analyzed for different microclimate thicknesses, external air temperature, external air velocity and optical properties of the fabric inner surface. The main conclusions of this study are as follows:

- The local transport rates between the clothing layer and the external air layer (i.e. the convective heat transfer coefficients obtained along the clothing) were found to strongly depend on the transport phenomena in the microclimate, in particular when natural convection is the prevailing transport mechanism in the microclimate. In such scenario, the convective heat transfer coefficient curves obtained along the clothing layer were found to markedly differ from those found in the literature for the typical case of air flow over a warm surface. The dependency between the transport rates of the internal and external flows was found to augment with the increasing importance of natural convection in the microclimate (and hence with decreasing emissivity of the fabric inner surface).

- The local heat transfer rate along the skin strongly depends on the flow patterns (and temperature distribution) prevailing in the clothing microclimates and can be markedly different from the average estimates obtained with correlations of the Nusselt number as a function of the Rayleigh number. The temperature distributions (and, hence, the heat transfer rates) in the microclimate are very sensitive to the characteristics of the external boundary layers forming along the clothing and to the distribution of temperature along the clothing, particularly for lowinsulation fabrics. The local heat transfer rates obtained along the microclimate are markedly different from those resulting from enclosures with constant-temperature active walls.

- The dependencies between the transport phenomena occurring inside and outside the clothing microclimate stress the importance of addressing, in a fully coupled way, both the calculation of the internal and external flows and the calculation of the heat transfer convection/radiation components. For low-insulation clothing, only a coupled approach guarantees accurate estimation of the local transfer rates along the skin and along the clothing.

The practical implications of the described work encompass different fields. The described approach can be used to study/predict the performance of CBRN garments regarding convective mass transfer of hazardous agents in the microclimates or to study/optimize the thermal performance of advanced clothing systems with embedded heating/cooling elements. It can also be used to analyze the accuracy of transport rates often used in analysis of the thermal strain imposed by garments. Finally, our results may promote a better understanding of data obtained during thermal characterization of thick porous fabric assemblies (affected by natural convection) or provide useful hints on the optimal placement of sensors inside the assemblies.

Acknowledgments The first author would like to thank J. B. L. M. Campos, from CEFT/FEUP, for valuable discussions and comments.

\section{References}

Bairi A, Laraqi N, García de María JM (2007) Numerical and experimental study of natural convection in tilted parallelepipedic cavities for large Rayleigh numbers. Exp Thermal Fluid Sci 31(4):309-324

Barker RL et al (2004) Modeling of thermal protection outfits for fire exposures F01-NS50. North Caroline State.

Bejan A, Kraus AD (2003) Heat transfer handbook. Wiley, Hoboken

Bogerd CP, Aerts J-M, Annaheim S, Bröde P, de Bruyne G, Flouris AD, Kuklane K, Mayor TS, Rossi RM (2015) A review on ergonomics of headgear: thermal effects. Int J Ind Ergon 45:1-12

Bröde P, De Bruyne G, Aerts J-M, Mayor TS, COST Action TU1101 WG4 (2014) Prediction of head sweat rates for assessing the thermal comfort of bicycle helmets. In: The 6th European conference on protective clothing (ECPC). Bruges, Belgium, p. 4

Çengel Y (2007) Heat and mass transfer: a practical approach, 3rd edn. McGraw-Hill Education, New York 
Corcione M (2003) Effects of the thermal boundary conditions at the sidewalls upon natural convection in rectangular enclosures heated from below and cooled from above. Int J Therm Sci 42(2):199-208

Coulson JM et al (1999) Chemical engineering volume 1-fluid flow, heat transfer and mass transfer, 6th edn. Butterworth-Heinemann, Oxford

Couto S, Campos JBLM, Mayor TS (2011) On the performance of a mitt heating multilayer: a numerical study. Int J Cloth Sci Technol 23(5): 373-387

Cuckovic-Dzodzo DM, Dzodzo MB, Pavlovic MD (1999) Laminar natural convection in a fully partitioned enclosure containing fluid with nonlinear thermophysical properties. Int J Heat Fluid Flow 20:614 623

de Vahl Davis G (1983) Natural convection of air in a square cavity: a bench mark numerical solution. Int J Numer Methods Fluids 3:249264

Ding D, Tang T, Song G, MacDonald A (2010) Characterizing the performance of a single-layer fabric system through a heat and mass transfer model. Part I: heat and mass transfer model. Text Res J 81(4):398-411

Ding D, Tang T, Song G, MacDonald A (2011) Characterizing the performance of a single-layer fabric system through a heat and mass transfer model. Part II: thermal and evaporative resistances. Text Res J 81(9):945-958

Gibson P (2009) Modeling heat and mass transfer from fabric-covered cylinders. J Eng Fibers Fabrics 4(1)

Hollands KG, Raithby GD, Konicek L (1975) Correlation equations for free convection heat transfer in horizontal layers of air and water. Int J Heat Mass Tranf 18:879-884

Hollands KG, Unny TE, Raithby GD, Konicek L (1976) Free convective heat transfer across inclined air layers. J Heat Transf 98(2):189-193

Khezzar L, Siginer D, Vinogradov I (2011) Natural convection in inclined two dimensional rectangular cavities. Heat Mass Transf 48(2):227239

Kim IY, Lee C, Li P, Corner BD, Paquette S (2002) Investigation of air gaps entrapped in protective clothing systems. Fire Mater 26:121126

Lartigue B, Lorente S, Bourret B (2000) Multicellular natural convection in a high aspect ratio cavity: experimental and numerical results. Int J Heat Mass Transf 43:3157-3170

Leal L (2007) Advanced transport phenomena: fluid mechanics and convective transport processes. Cambridge University Press, New York

Lee JR, Ha MY (2005) A numerical study of natural convection in a horizontal enclosure with a conducting body. Int J Heat Mass Transf 48(16):3308-3318

Li J, Lu Y, Li X (2012) Effect of relative humidity coupled with air gap on heat transfer of flame-resistant fabrics exposed to flash fires. Text Res J 82(12):1235-1243

Lienhard VJ, Lienhard J IV (2003) A heat transfer textbook, 3rd edn. Phlogiston, Cambridge

Mayor TS, Couto S, Psikuta A, Rossi RM (2014a) A numerical analysis on the transport phenomena across horizontal clothing microclimates. In: The 6th European conference on protective clothing (ECPC). Bruges, Belgium, p. 34

Mayor TS, Couto S, Psikuta A, Rossi RM (2014b) Transport phenomena in clothing wavy microclimates - a numerical study. In: Scientific conference for smart and functional textiles, well-being, thermal comfort in clothing, design, thermal manikins and modelling (Ambience14 \& 10i3m). Tampere, Finland

Mayor TS, Oliveira D, Rossi RM, Annaheim S (2015) Numerical simulation of the transport phenomena in tilted clothing microclimates. In: XVI international conference on environmental ergonomics (ICEE'15). Portsmouth, UK

Min K, Son Y, Kim C, Lee Y, Hong K (2007) Heat and moisture transfer from skin to environment through fabrics: a mathematical model. Int J Heat Mass Transf 50(25-26):5292-5304
Morozumi Y, Akaki K, Tanabe N (2012) Heat and moisture transfer in gaps between sweating imitation skin and nonwoven cloth: effect of gap space and alignment of skin and clothing on the moisture transfer. Heat Mass Transf 48(7):1235-1245

Morrissey MP, Rossi RM (2013) The effect of wind, body movement and garment adjustments on the effective thermal resistance of clothing with low and high air permeability insulation. Text Res J 84(6):583592

Neiva O, Pinho FT, Mayor TS (2011) A numerical study on the cooling power of an enhanced convection solution for footwear. In JapanPortugal Nano-Biomedical Engineering Symposium 2011. Porto, p. 2.

Neves SF, Campos JBLM, Mayor TS (2012) Numerical simulation study on the heat and mass transfer through multi-layer textile assemblies. In Comsol Conference Europe. Milan

Neves SF, Campos JBLM, Mayor TS (2014) A numerical simulation study on the thermal performance of ventilated clothes. In: The 6th European conference on protective clothing (ECPC). Bruges, Belgium, p. 13

Neves SF, Campos JBLM, Mayor TS (2015a) On the determination of parameters required for numerical studies of heat and mass transfer through textiles - methodologies and experimental procedures. Int J Heat Mass Transf 81:272-282

Neves SF, Couto S, Campos JBLM, Mayor TS (2015b) Advances in the optimisation of apparel heating products: a numerical approach to study heat transport through a blanket with an embedded smart heating system. Accepted in Applied Thermal Engineering. doi:10.1016/j.applthermaleng.2015.05.035

Psikuta A, Frackiewicz-Kaczmarek J, Frydrych I, Rossi RM (2012) Quantitative evaluation of air gap thickness and contact area between body and garment. Text Res J 82(14):1405-1413

Ridouane EH, Hasnaoui M, Campo A (2005) Effects of surface radiation on natural convection in a Rayleigh-Benard square enclosure: steady and unsteady conditions. Heat Mass Transf 42(3):214-225

Rocha R, Neiva O, Campos JBLM, Pinho FT, Mayor TS (2012) A cooling solution for footwear-numerical analysis. In: The Fiber Society 2012 spring conference-fiber research for tomorrow's applications. St. Gallen, Switzerland, pp. 230-231

Sawcyn CMJ, Torvi DA (2009) Improving heat transfer models of air gaps in bench top tests of thermal protective fabrics. Text Res J 79(7):632-644

Scott RA (ed) (2005) Textiles for protection. Woodhead, Cambridge

Sobera MP (2006) Flow, heat and mass transfer through protective textiles. Tecnische Universiteit Czçestochowa geboren te Ilza, Polen

Song G (2007) Clothing air gap layers and thermal protective performance in single layer garment. J Ind Text 36(3):193-205

Soong CY, Tzeng PY, Chiang DC, Sheu TS (1996) Numerical study on mode-transition of natural convection in differentially heated inclined enclosures. Int J Heat Mass Transf 39:2869-2882

Souza MD, Miranda RFD, Machado HA (2003) Natural convection in enclosures with variable fluid properties. Int J Numer Methods Heat Fluid Flow 13(8):1079-1096

Torvi DA, Douglas Dale J, Faulkner B (1999) Influence of air gaps on bench-top test results of flame resistant fabrics. J Fire Prot Eng 10(1):1-12

Vierendeels J, Merci B, Dick E (2003) Benchmark solutions for the natural convective heat transfer problem in a square cavity with large horizontal temperature differences. Int J Numer Methods Heat Fluid Flow 13(8):1057-1078

Vivek V, Sharma AK, Balaji C (2012) Interaction effects between laminar natural convection and surface radiation in tilted square and shallow enclosures. Int J Therm Sci 60:70-84

Wang H, Hamed MS (2006) Flow mode-transition of natural convection in inclined rectangular enclosures subjected to bidirectional temperature gradients. Int J Therm Sci 45(8):782-795 
Wang F, Lin LY, Ribeiro M, Ferraro S, Mayor TS, Molinaro V, Gao C, Kuklane K, Holmér I (2011) Localized evaporative resistance: correction for body and air movement. In: Stylianos Kounalakis, Maria Koskolou (Eds), ed. XIV International conference on environmental ergonomics (ICEE'11). Nafplio, Greece, pp. 101-102.

Wang F, Ferraro S, Lin LY, Mayor TS, Molinaro V, Ribeiro M, Gao C, Kuklane K, Holmér I (2012) Localised boundary air layer and clothing evaporative resistances for individual body segments. Ergonomics 55(7):799-812

Zhang H, Hu TL, Zhang JC (2009) Surface emissivity of fabric in the 8 $14 \mu \mathrm{m}$ waveband. J Text Inst 100(1):90-94

Zhao M, Gao C, Wang F, Kuklane K, Holmér I, Li J (2013) A study on local cooling of garments with ventilation fans and openings placed at different torso sites. Int J Ind Ergon 43(3):232-237 